\title{
Do early infant feeding practices vary by maternal ethnic group?
}

\author{
Lucy J Griffiths*, A Rosemary Tate †, Carol Dezateux and the Millennium Cohort Study Child \\ Health Group $\ddagger$ \\ MRC Centre of Epidemiology for Child Health, UCL Institute of Child Health, 30 Guilford Street, London \\ WCIN IEH, UK
}

Submitted 26 July 2006: Accepted 21 November 2006: First published online 6 March 2007

\begin{abstract}
Objective: To examine UK country and ethnic variations in infant feeding practices. Design: Cohort study.

Setting: Infants enrolled in the Millennium Cohort Study, born between September 2000 and January 2002.

Subjects: A total of 18150 natural mothers (11286 (8207 white) living in England) of singleton infants.

Outcome measures: Breast-feeding initiation, breast-feeding discontinuation and introduction of solid foods before 4 months.

Explanatory variables: Maternal ethnic group, education and social class.

Results: Seventy per cent of UK mothers started to breast-feed, of whom 62\% stopped before 4 months. Median age at discontinuing breast-feeding was 14, 13, 10 and 6 weeks in Scotland, England, Wales and Northern Ireland, respectively. Thirty-six per cent of UK mothers (34\% in England) introduced solids before 4 months. White mothers were more likely to discontinue breast-feeding (62\%) and introduce solids early (37\%) than most other ethnic minority groups; those stopping before 4 months were more likely to introduce solids early compared with those continuing to breastfeed beyond this age (adjusted rate ratio (95\% confidence interval): $1.3(1.1-1.2)$ ). Educated mothers were less likely to stop breast-feeding before 4 months (white mothers, 0.8 (0.8-0.9); non-white mothers, $0.9(0.8-1.0))$ than those with no/minimal qualifications but, among ethnic minorities, were more likely to introduce solids early (1.3 (1.0-1.6)). Socio-economic status was positively associated with breast-feeding continuation among white women, and with age at introduction of solids among nonwhite women.

Conclusions: We have identified important geographic, ethnic and social inequalities in breast-feeding continuation and introduction of solids within the UK, many of which have not been reported previously. The factors mediating these associations are complex and merit further study to ensure that interventions proposed to promote maternal adherence to current infant feeding recommendations are appropriate and effective.
\end{abstract}

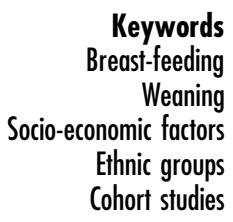

Keywords st-feeding Weaning

Ethnic groups Cohort studies
The benefits of breast-feeding for the health of mothers and their children are well established ${ }^{1}$. The 1994 UK government recommendation to delay introduction of solid foods until 4-6 months of age ${ }^{2}$ was revised in 2003 to reflect updated World Health Organization guidelines to breast-feed exclusively for the first 6 months, before introducing complementary foods or drink ${ }^{3}$. There is

\footnotetext{
${ }^{\dagger}$ Present address: Department of Biostatistics and Computing, Institute of Psychiatry, King's College London, De Crespigny Park, London SE5 8AF, UK.

${ }^{\ddagger}$ Other members of the Millennium Cohort Study Child Health Group: Suzanne Bartington, Dr Helen Bedford, Professor Tim Cole, Summer Sherburne Hawkins, Dr Catherine Law, Professor Catherine Peckham, Dr Lamiya Samad and Dr Suzanne Walton.
}

evidence that early breast-feeding discontinuation and introduction of solid foods may be associated with excessive weight gain, and an increased risk of respiratory and gastrointestinal illness ${ }^{4-7}$. Despite this, many mothers in the UK do not breast-feed for 4 or 6 months, either at all or exclusively, and introduce solids into their infant's diet before they are 4 months old ${ }^{7-10}$.

We have previously shown that maternal ethnicity is an important determinant of breast-feeding initiation in the UK, with white women being less likely to breast-feed than women from all other ethnic groups ${ }^{11}$. In contrast, although there is also some evidence regarding ethnic differences in early weaning ${ }^{9,12}$, the process of gradual replacement of milk by solid food ${ }^{13}$, the previous 
quinquennial infant feeding surveys in the UK have not reported multivariable analysis and so the extent to which these are mediated by other maternal characteristics, such as socio-economic status and educational attainment, remains unclear.

The Millennium Cohort Study (MCS) is a longitudinal survey of the health and development of nearly 19000 babies across the UK, designed to over-represent children from ethnic minorities or socially disadvantaged backgrounds ${ }^{14}$. We used data from this study to examine country and ethnic variation in infant feeding practices, and the extent to which ethnic variations are mediated by differences in maternal educational and socio-economic status. Specifically, we investigated the characteristics of mothers who either discontinued breast-feeding or introduced solids before their infant was aged 4 months.

\section{Methods}

\section{Study population}

The MCS comprises 18819 babies born between September 2000 and January 2002, living in the UK at age 9 months, and eligible for Child Benefit - a universal benefit available to all families. A disproportionately stratified cluster sampling design was used to overrepresent children living in Scotland, Northern Ireland and Wales, in disadvantaged residential areas or those of high ethnic minority prevalence. Within England, electoral wards (as existent in 1998) were defined as ethnic (at least $30 \%$ of residents 'black' or 'Asian' from 1991 census data) and the remainder as 'disadvantaged' (in the upper quartile of the ward-based Child Poverty Index) or 'advantaged' (not in the upper quartile). For Wales, Scotland and Northern Ireland, there was no ethnic stratum. Full details of the sampling design are reported elsewhere ${ }^{15}$; the overall response rate was $72 \%$.

Information on infant feeding practices, maternal education, socio-economic status and ethnicity was obtained during a home interview when cohort infants were approximately 9 months old. All interviews were conducted using a piloted, standardised interview schedule by trained interviewers. We examined country differences in infant feeding practices for 18150 natural mothers of singleton cohort infants living in the UK, and ethnic differences for 11286 mothers in England, where most mothers from ethnic minorities lived.

\section{Outcome measures}

We defined the following outcomes: (1) early discontinuation of breast-feeding, the proportion of cohort mothers who, having started breast-feeding, stopped giving any breast milk before four calendar months (17.4 weeks); and (2) early introduction of solid foods, the proportion of all cohort mothers introducing solids before four calendar months, and obtained in response to the following question: 'How old was $\wedge$ cohort baby's name $\wedge$ when she/he first had any solid food such as cereal or rusk?' We reported breast-feeding initiation as the proportion of all cohort mothers who put their baby to the breast at least once and gave any breast milk ${ }^{11}$. We selected 4 months to reflect the recommendation in place at the time cohort infants were born, and examined any breast-feeding since only $4 \%$ of cohort infants were fully breast-fed for at least 4 months ${ }^{11}$.

\section{Explanatory variables}

Maternal ethnic group was described using Office for National Statistics guidelines ${ }^{16}$, with white women further categorised as 'white' (of British or Irish origin) or 'other white' (from other European or other countries). Of the 11286 mothers within England, 8207 (weighted percentage: 85\%) were white, 281 (3\%) 'other white' (191 from other European countries), 452 (2\%) Indian, 857 (3\%) Pakistani, 356 (1\%) Bangladeshi, 249 (1\%) black Caribbean, 358 (2\%) black African, 336 (2\%) of 'other' ethnicity and 165 (1\%) of mixed ethnicity. Maternal socioeconomic status was classified using the National Statistics Socio-Economic Classification ${ }^{17}$, maternal educational qualifications as 'some' (GCSE grades A-C or above) or none/minimal, and maternal employment status as returned to work before 4 months or not. Information was also available regarding lone mother status (at interview), parity and maternal age at first motherhood and at cohort birth.

\section{Statistical analyses}

Poisson regression was used to calculate rate ratios as a measure of relative risks ${ }^{18}$. All maternal characteristics identified as being significant $(P<0.05)$ in the univariable analysis were retained in the multivariable analyses. Effect modifiers of ethnicity were identified by examining interactions between ethnicity and the other explanatory variables; results of subgroup analyses are reported where the relevant whole group interaction term was significant $(P<0.05)$ in the adjusted analysis. All analyses were conducted using STATA 8.2 (Stata Corporation) using sample weights and SVY commands to allow for the sampling design, thus producing results that are generalisable to the UK and to obtain robust standard errors for the Poisson regression.

\section{Results}

In the UK as a whole, $70 \%$ of mothers started to breastfeed $^{11}$, of whom $62 \%$ stopped before 4 months. The proportion discontinuing breast-feeding at this age was highest in Northern Ireland and lowest in Scotland (Table 1). The median age at discontinuing breast-feeding was 14, 13, 10 and 6 weeks in Scotland, England, Wales and Northern Ireland, respectively. Solids were introduced before 4 months by 36\% of all mothers; this was lowest in England, and more common among mothers who had never breast-fed (43\%), or who discontinued 
Table 1 Infant feeding practices in the UK and by UK country

\begin{tabular}{llllll}
\hline & Wales & England & Scotland & Northern Ireland & UK \\
\hline$\%^{*}(n)$ of all infants who had any breast milk $(\mathrm{A})$ & $63(1587)$ & $72(8034)$ & $65(1421)$ & $51(896)$ & $70(11938)$ \\
$\%^{*}(n)$ of A who breast fed for $<4$ months $\dagger$ & $66(1092)$ & $60(4871)$ & $58(846)$ & $73(670)$ & $62(7479)$ \\
$\%^{*}(n)$ introduced solids before 4 months & $41(1107)$ & $34(3497)$ & $39(885)$ & $41(762)$ & $36(6251)$
\end{tabular}

Missing number of cases for UK: infants who had any breast milk (3), introduced solids before 4 months (4).

*Weighted for design effect.

†17.4 weeks.

breast-feeding before 4 months (39\%), than among those who had ever breast-fed (31\%), or breast-fed for at least 4 months (25\%) (data not shown). The proportion of mothers stopping breast-feeding increased steadily with increasing infant age, and by 6 months $78 \%$ of mothers had stopped any breast-feeding (Fig. 1). About one-fifth of mothers had introduced solids by 3 months of age, with a sharp increase between 16 and 18 weeks, such that over half $(51 \%)$ had introduced solids at 4 months.

The remaining analyses are based on cohort mothers living in England ( $n=11286$ ), of whom 3941 (34\%) were in semi-routine occupations, 1504 (7\%) were long-term unemployed or never employed, 3583 (26\%) had no or minimal educational qualifications, and 1804 (13\%) were lone mothers. The median (interquartile range) age at first motherhood was 25 (20-29) years and, at birth of the cohort member, 29 (24-33) years. A total of 4595 (43\%) of the cohort babies were first born.

Infant feeding practices varied by maternal ethnic group (Fig. 2). In unadjusted analyses, Bangladeshi, Pakistani and white mothers were the most likely to stop breastfeeding before 4 months (66, 64 and 62\%, respectively), while black African mothers and those from 'other white' or 'other ethnic' groups were the least likely (38, 48 and $40 \%$, respectively). In contrast, white, black Caribbean and other white mothers were more likely to introduce solids early (37, 20 and 19\%, respectively), with Pakistani and Bangladeshi mothers, and those from 'other ethnic' groups, least likely to do so (12\%, 14 and $12 \%$, respectively).

After adjustment for maternal education, socio-economic status, employment, age, parity and lone parenthood, mothers from most ethnic minority groups, including 'other whites' but excluding Pakistani and Bangladeshi mothers, were less likely to stop breastfeeding before 4 months than white mothers (Table 2). Mothers who returned to work before 4 months were more likely to discontinue breast-feeding early, as were lone mothers and those who introduced solids before 4 months.

Mothers from all ethnic minority groups were less likely to introduce solids early than white mothers after adjustment for maternal characteristics (Table 3). Those who returned to work before 4 months were more likely to start solids early.

Interaction terms for socio-economic status and ethnic group, and for educational qualifications and ethnic group, were significant for breast-feeding discontinuation and for introduction of solids before 4 months. We stratified mothers according to whether they were or were not 'white' in order to examine these associations further (Table 4). Among non-white mothers, those with educational qualifications were less likely to stop breastfeeding before 4 months, but more likely to introduce solids early. Among white mothers, education was related to breast-feeding continuation, but not to introduction of solids.

Socio-economic status was associated with breastfeeding continuation among white, but not non-white, women. White mothers from managerial, professional and intermediate occupations were less likely to stop breast-feeding before 4 months than those in semiroutine and routine occupations. In contrast, non-white mothers from managerial and professional occupations were significantly more likely to introduce solids early (Table 4).

Associations between breast-feeding continuation and introduction of solids also differed according to maternal ethnicity (Table 4): after adjustment, white women who had discontinued breast-feeding before 4 months were more likely to introduce solids before 4 months than those who had not discontinued breast-feeding. Although the point estimate for this association was similar for nonwhite women, this did not reach statistical significance as the number of non-white women discontinuing breastfeeding and introducing solids before 4 months was small $(n=270)$.

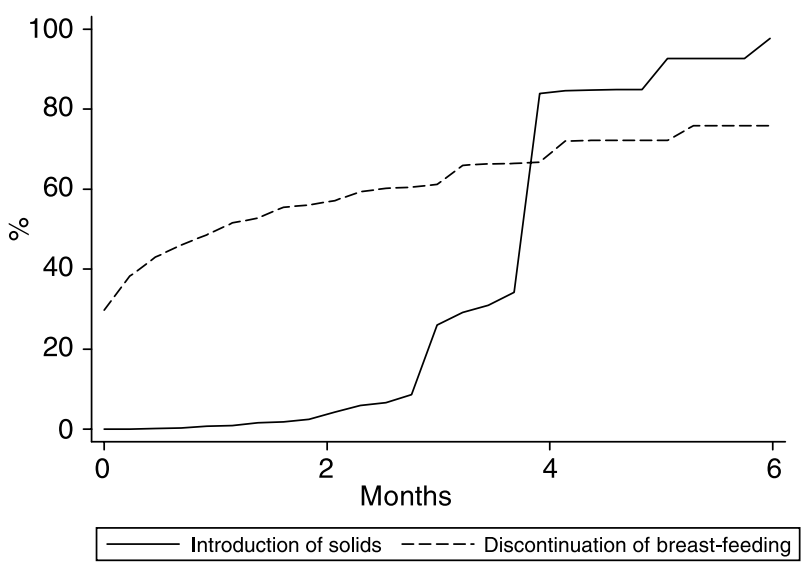

Fig. 1 Weighted percentage of all mothers in the UK introducing solid foods and discontinuing breast milk over time 


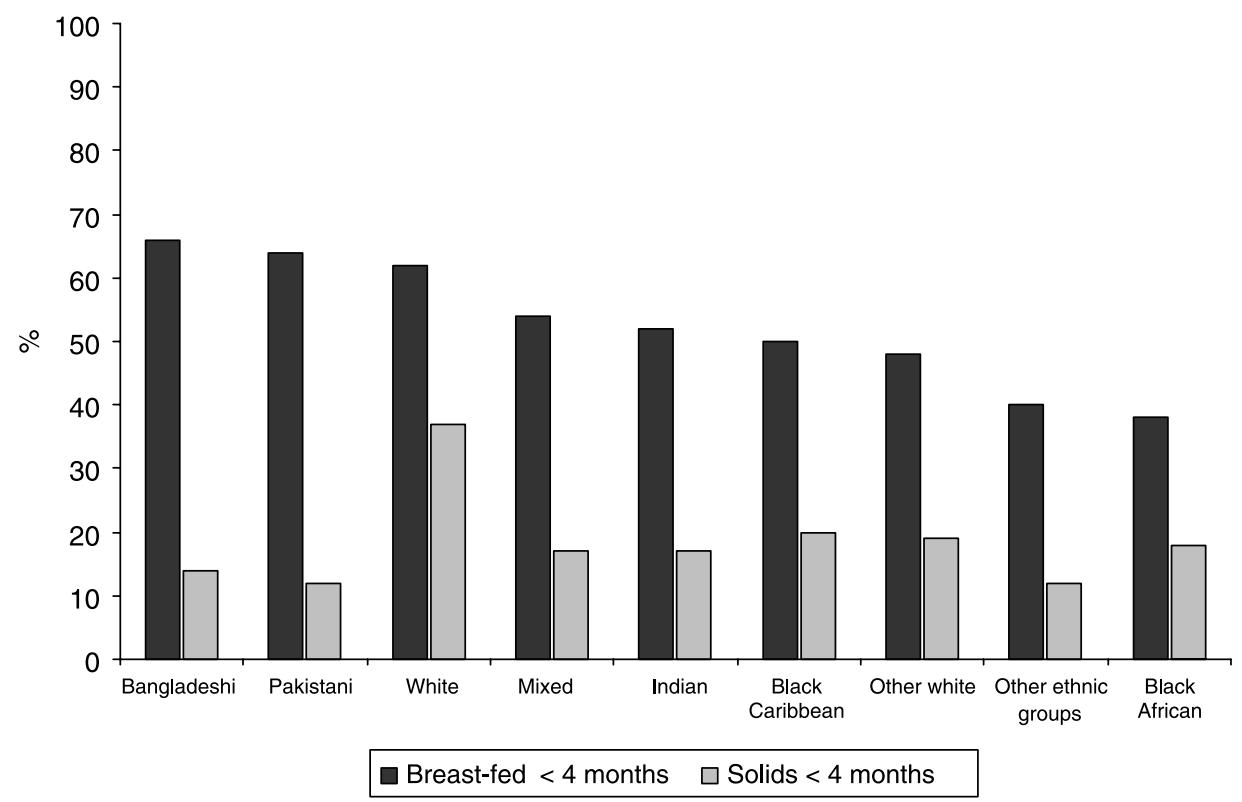

Fig. 2 Infant feeding practices by maternal ethnic group: England only

Table 2 Maternal ethnicity and other factors associated with discontinuing breast-feeding before 4 months: England (weighted percentages, rate ratios and confidence intervals)

\begin{tabular}{|c|c|c|c|}
\hline Measures & $\%(n)$ & $\begin{array}{c}\text { Unadjusted } \\
\text { RR }(95 \% \mathrm{Cl})\end{array}$ & $\begin{array}{c}\text { Adjusted } \\
\operatorname{RR}^{\star}(95 \% \mathrm{Cl})\end{array}$ \\
\hline \multicolumn{4}{|l|}{ Ethnic group } \\
\hline White & $62(5426)$ & 1.0 & 1.0 \\
\hline Other white & $48(260)$ & $0.8(0.7-0.9)$ & $0.8(0.7-1.0)$ \\
\hline Mixed & $54(140)$ & $0.9(0.7-1.0)$ & $0.8(0.7-0.9)$ \\
\hline Indian & $52(381)$ & $0.9(0.7-1.0)$ & $0.9(0.8-1.0)$ \\
\hline Pakistani & $64(623)$ & $1.0(0.9-1.1)$ & $1.0(0.9-1.1)$ \\
\hline Bangladeshi & $66(312)$ & $1.1(1.0-1.2)$ & $1.0(0.9-1.1)$ \\
\hline Black Caribbean & $50(231)$ & $0.8(0.7-0.9)$ & $0.9(0.8-1.0)$ \\
\hline Black African & $38(334)$ & $0.6(0.5-0.7)$ & $0.7(0.5-0.9)$ \\
\hline Other ethnic group & $40(310)$ & $0.7(0.5-0.8)$ & $0.7(0.6-0.8)$ \\
\hline \multicolumn{4}{|l|}{ Socio-economic status } \\
\hline Managerial and professional occupations & $50(2486)$ & $0.7(0.7-0.8)$ & $0.8(0.8-0.9)$ \\
\hline Small employers and own account workers & $61(1390)$ & $0.9(0.8-0.9)$ & $1.0(0.9-1.0)$ \\
\hline Intermediate occupations & $56(333)$ & $0.8(0.7-0.9)$ & $0.8(0.7-0.9)$ \\
\hline Lower supervisory and technical occupations & $70(375)$ & $1.0(0.9-1.1)$ & $1.0(1.0-1.1)$ \\
\hline Semi-routine and routine occupations & $70(2343)$ & 1.0 & 1.0 \\
\hline Never worked and long-term unemployed & $63(1008)$ & $0.9(0.8-1.0)$ & $1.0(0.9-1.0)$ \\
\hline \multicolumn{4}{|l|}{ Educational qualifications } \\
\hline None or minimal & 74 (2045) & 1.0 & 1.0 \\
\hline Somet & 56 (5968) & $0.8(0.7-0.8)$ & $0.9(0.8-0.9)$ \\
\hline \multicolumn{4}{|l|}{ Employment status } \\
\hline Returned to work before 4 months & $73(1309)$ & 1.0 & 1.0 \\
\hline Did not return to work before 4 months & 57 (6720) & $0.8(0.7-0.8)$ & $0.8(0.8-0.8)$ \\
\hline \multicolumn{4}{|l|}{ Lone mother status } \\
\hline Lone mother & $72(979)$ & 1.0 & 1.0 \\
\hline Non-lone mother & 58 (7055) & $0.8(0.8-0.9)$ & $0.9(0.9-1.0)$ \\
\hline \multicolumn{4}{|l|}{ Introduced solids before 4 months } \\
\hline No & $56(5829)$ & 1.0 & 1.0 \\
\hline Yes & 67 (2203) & $1.2(1.2-1.3)$ & $1.1(1.1-1.2)$ \\
\hline
\end{tabular}

$n=$ all women within England who initiated breast-feeding; $\mathrm{RR}$ - rate ratio; $\mathrm{Cl}$ - confidence interval.

Missing number of cases: ethnic group (17), socio-economic status (99), educational qualifications (21), employment status (5), age at Millennium Cohort Study birth (4), age at first ever live birth (386), parity (5). *Adjusted for age at first motherhood, age at cohort baby's birth, parity and all other variables within the group.

†Qualifications include degree, diploma, A/AS/S levels, GCSE grades A-C, other or overseas qualifications. 
Table 3 Maternal ethnicity and other factors associated with introducing solids before 4 months: England (weighted percentages, rate ratios and confidence intervals)

\begin{tabular}{|c|c|c|c|}
\hline Measures & $\%(n)$ & $\begin{array}{c}\text { Unadjusted } \\
\text { RR }(95 \% \mathrm{Cl})\end{array}$ & $\begin{array}{c}\text { Adjusted* } \\
\text { RR }(95 \% \mathrm{Cl})\end{array}$ \\
\hline \multicolumn{4}{|l|}{ Ethnic group } \\
\hline White & 37 (8207) & 1.0 & 1.0 \\
\hline Other white & $19(281)$ & $0.5(0.4-0.7)$ & $0.6(0.5-0.8)$ \\
\hline Mixed & $17(165)$ & $0.5(0.3-0.7)$ & $0.5(0.3-0.7)$ \\
\hline Indian & $17(452)$ & $0.5(0.4-0.6)$ & $0.5(0.3-0.6)$ \\
\hline Pakistani & $12(857)$ & $0.3(0.2-0.4)$ & $0.3(0.2-0.4)$ \\
\hline Bangladeshi & $14(356)$ & $0.4(0.3-0.5)$ & $0.4(0.3-0.6)$ \\
\hline Black Caribbean & $20(249)$ & $0.6(0.4-0.7)$ & $0.5(0.4-0.7)$ \\
\hline Black African & $18(358)$ & $0.5(0.4-0.6)$ & $0.6(0.5-0.7)$ \\
\hline Other ethnic group & $12(336)$ & $0.3(0.2-0.5)$ & $0.4(0.2-0.6)$ \\
\hline \multicolumn{4}{|l|}{ Socio-economic status } \\
\hline Managerial and professional occupations & $31(2850)$ & $0.8(0.7-0.9)$ & $1.0(0.9-1.1)$ \\
\hline Small employers and own account workers & 33 (1868) & $0.9(0.8-0.9)$ & $1.0(0.9-1.0)$ \\
\hline Intermediate occupations & $36(421)$ & $0.9(0.8,1.1)$ & $1.1(0.9-1.3)$ \\
\hline Lower supervisory and technical occupations & $38(557)$ & $1.0(0.9-1.1)$ & $1.0(0.9,1.1)$ \\
\hline Semi-routine and routine occupations & 38 (3941) & 1.0 & 1.0 \\
\hline Never worked and long-term unemployed & $25(1504)$ & $0.7(0.6-0.8)$ & $0.9(0.8-1.0)$ \\
\hline \multicolumn{4}{|l|}{ Educational qualifications } \\
\hline None or minimal & $36(3583)$ & 1.0 & 1.0 \\
\hline Some† & $33(7675)$ & $0.9(0.8-1.0)$ & $1.0(0.9-1.1)$ \\
\hline \multicolumn{4}{|l|}{ Employment status } \\
\hline Returned to work before 4 months & 39 (1888) & 1.0 & 1.0 \\
\hline Did not return to work before 4 months & 33 (9393) & $0.8(0.8-0.9)$ & $0.9(0.9-1.0)$ \\
\hline \multicolumn{4}{|l|}{ Lone mother status } \\
\hline Lone mother & $37(1804)$ & 1.0 & 1.0 \\
\hline Non-Ione mother & 33 (9482) & $0.9(0.8-1.0)$ & $1.1(1.0-1.1)$ \\
\hline \multicolumn{4}{|l|}{ Discontinued breast-feeding before 4 months } \\
\hline No & $25(3163)$ & 1.0 & 1.0 \\
\hline Yes & $37(8121)$ & $1.5(1.4-1.6)$ & $1.3(1.2-1.4)$ \\
\hline
\end{tabular}

$n=$ all women; $\mathrm{RR}$ - rate ratio; $\mathrm{Cl}$ - confidence interval.

Missing number of cases: ethnic group (25), socio-economic status (145), educational qualifications (28), employment status (5), age at Millennium Cohort Study birth (5), age at first ever live birth (506), parity (6), discontinued breastfeeding before 4 months (2).

*Adjusted for age at first motherhood, age at cohort baby's birth, parity and all other variables within the group.

†Qualifications include degree, diploma, A/AS/S levels or GCSE grades A-C.

\section{Discussion}

\section{Statement of principal findings}

We have found that, overall in the UK, two-thirds of mothers who started to breast-feed stopped before their infant was 4 months old, and one-third of all mothers started to feed their infants solids before this age. This was more marked for mothers living in Northern Ireland and Wales. These early weaning practices were strongly associated with maternal ethnic group, with most nonwhite mothers being less likely to stop breast-feeding early or to introduce solids early than their white counterparts. We found that the association of maternal education with infant feeding practices varied by maternal ethnic group, with non-white mothers with educational qualifications more likely to introduce solids early and the converse finding among white mothers. Similarly, socio-economic status was associated only with breast-feeding continuation among white women and with age at introduction of solids among non-white women. Finally, we found evidence to suggest that these behaviours were correlated, in that mothers who had stopped breast-feeding before 4 months were more likely to start solids early, although this was not statistically significant for non-white mothers.

\section{Strengths and weaknesses of the study}

One advantage afforded by the MCS is that it represents a heterogeneous and contemporary cohort of mothers, sampled to over-represent those living in disadvantaged circumstances and from ethnic minorities. Although previous surveys have reported that early weaning practices vary among certain maternal ethnic groups ${ }^{9,12}$, as far as we are aware ours is the first study to examine these ethnic patterns in the UK more fully, including their relationship to maternal education and socio-economic status.

Information on infant feeding within the MCS was obtained from maternal recall at 9 months, and our figures accord with those collected prospectively in the UK Infant Feeding Survey $2000^{9}$. Others have shown maternal recall of breast-feeding duration, and the circumstances of pregnancy and delivery, to be reliable and valid ${ }^{19,20}$. However, previous surveys of early weaning practices across the UK have suggested relatively more women introducing solids early than reported here ${ }^{7-9}$, possibly reflecting differences in survey questions and maternal reporting practices in rounding to the nearest month. We did not examine other forms of infant feeding, including use of formula or other types of milk, such as soya or cow's 
Table 4 Factors associated with stopping breast-feeding and introducing solids before 4 months: white and non-white mothers* in England (rate ratios and confidence intervals)

\begin{tabular}{|c|c|c|}
\hline & $\begin{array}{c}\text { Breast-feeding } \\
<4 \text { months } \dagger\end{array}$ & $\begin{array}{c}\text { Solids } \\
<4 \text { months } \ddagger\end{array}$ \\
\hline \multicolumn{3}{|l|}{ White } \\
\hline \multicolumn{3}{|l|}{ Socio-economic status } \\
\hline Managerial and professional occupations & $0.8(0.8-0.9)$ & $1.0(0.9-1.1)$ \\
\hline Small employers and own account workers & $1.0(0.9-1.0)$ & $1.0(0.9-1.0)$ \\
\hline Intermediate occupations & $0.8(0.8-1.0)$ & $1.1(0.9-1.3)$ \\
\hline Lower supervisory and technical occupations & $1.0(0.9-1.1)$ & $1.0(0.9-1.1)$ \\
\hline Semi-routine and routine occupations & 1.0 & 1.0 \\
\hline Never worked and long-term unemployed & $1.0(0.9-1.1)$ & $0.9(0.8-1.1)$ \\
\hline \multicolumn{3}{|l|}{ Educational qualifications } \\
\hline None or minimal & 1.0 & 1.0 \\
\hline Some§ & $0.8(0.8-0.9)$ & $1.0(0.9-1.0)$ \\
\hline \multicolumn{3}{|l|}{ Discontinued breast-feeding before 4 months } \\
\hline No & - & 1.0 \\
\hline Yes & - & $1.3(1.2-1.5)$ \\
\hline \multicolumn{3}{|l|}{ Introduced solids before 4 months } \\
\hline No & 1.0 & - \\
\hline Yes & $1.3(1.1-1.2)$ & - \\
\hline \multicolumn{3}{|l|}{ Non-white } \\
\hline \multicolumn{3}{|l|}{ Socio-economic status } \\
\hline Managerial and professional occupations & $0.9(0.8-1.1)$ & $1.5(1.0-2.0)$ \\
\hline Small employers and own account workers & $1.0(0.8-1.1)$ & $1.0(0.7-1.5)$ \\
\hline Intermediate occupations & $0.9(0.6-1.3)$ & $0.7(0.4-1.4)$ \\
\hline Lower supervisory and technical occupations & $1.2(1.0-1.5)$ & $1.2(0.7-2.0)$ \\
\hline Semi-routine and routine occupations & 1.0 & 1.0 \\
\hline Never worked and long-term unemployed & $1.0(0.9-1.1)$ & $0.7(0.5-1.0)$ \\
\hline \multicolumn{3}{|l|}{ Educational qualifications } \\
\hline None or minimal & 1.0 & 1.0 \\
\hline Some§ & $0.9(0.8-1.0)$ & $1.3(1.0-1.6)$ \\
\hline \multicolumn{3}{|l|}{ Discontinued breast-feeding before 4 months } \\
\hline No & - & 1.0 \\
\hline Yes & - & $1.2(0.9-1.5)$ \\
\hline \multicolumn{3}{|l|}{ Introduced solids before 4 months } \\
\hline No & 1.0 & - \\
\hline Yes & $1.1(1.0-1.3)$ & - \\
\hline
\end{tabular}

*Includes all ethnic minority groups and women classified as 'other white' (see Methods).

† Analysis includes all women who initiated breast-feeding. Adjusted for socio-economic status, educational qualifications, employment status, lone mother status, age at Millennium Cohort Study birth, age at first live birth, parity and solids.

$\ddagger$ Analysis includes all women. Adjusted for socio-economic status, educational qualifications, employment status, lone mother status, age at Millennium Cohort Study birth, age at first live birth, parity and breast-feeding.

$\S$ Qualifications include degree, diploma, A/AS/S levels or GCSE grades A-C.

milk, as this detailed information was not collected within the cohort survey ${ }^{21}$.

\section{Comparison offindings with otber studies}

As discussed previously, the proportion of mothers introducing solids early is lower in the MCS than reported previously for the $\mathrm{UK}$, and this is also evident when data for individual countries are compared ${ }^{7,9,12}$. However, our findings are similar to those of the Infant Feeding Survey ${ }^{9}$ which found that mothers in Northern Ireland were more likely to start solids earlier than mothers in other countries. Furthermore, our estimates of breast-feeding duration by UK country are comparable with those of previous reports that mothers in Scotland breast-feed longer, while those in Northern Ireland discontinue breast-feeding earlier? Within the MCS, we have shown that mothers are more likely to introduce solids early if they discontinued breast-feeding early. This is to our knowledge a novel finding which warrants further exploration.

Previous information on ethnic differences in early infant feeding practices in the UK is limited to the Infant Feeding Survey ${ }^{9}$, which included only 619 women from non-white ethnic groups, and an earlier survey of infant feeding practices confined to Asian families living in England $^{12}$. Data from the ethnically diverse MCS has enabled examination of ethnic differences in greater detail, allowing white women to be further categorised as of British/Irish origin or not. Overall, white women reported less adherence to recommended infant feeding practices than women from other ethnic groups and white woman from other European or other countries. This is consistent with the UK's poor record of breast-feeding in Europe $^{22}$. Our finding of ethnic variations in the introduction of solids is, to our knowledge, novel, and is 
consistent with our previous report of similar ethnic gradients in breast-feeding initiation ${ }^{11}$.

Associations between socio-economic status and continuation of breast-feeding also differed according to maternal ethnicity. Socio-economic status was associated with breast-feeding continuation among white, but not non-white, women. Although socio-economic status has previously been reported to be associated with early introduction of solids ${ }^{7,23}$, we found this to be the case only for non-white women. Similarly, we have found ethnic differences in associations with maternal education: among non-white mothers, those with educational qualifications were less likely to stop breast-feeding early than those with no or minimal qualifications, but more likely to introduce solids before 4 months. This is consistent with some ${ }^{10}$, but not $\mathrm{all}^{8}$, previous reports, and highlights the complex pathways that mediate women's infant feeding decisions and their variation by maternal ethnicity.

Other maternal socio-economic factors also have a significant bearing on infant feeding practices. Literature on maternal employment and infant feeding is sparse, but our findings are consistent with previous reports that mothers who return to work before 4 months are more likely to discontinue breast-feeding and introduce solids early $^{24}$. We have reported previously that lone mothers are less likely to start breast-feeding ${ }^{11}$. In the current study, we have found that they are also more likely to stop breastfeeding before 4 months, but are neither more nor less likely to start solids early.

\section{Implications of the study for clinicians and policy-makers}

Our findings underline the need for policies that support continuation, and not just initiation, of breast-feeding ${ }^{25}$. Consideration should also be given as to how policies on early nutrition can promote the later introduction by mothers of solid foods in their infant's diet ${ }^{26}$. There is some evidence to suggest that interventions such as peer support and support by suitably trained health professionals during the postnatal period are effective in prolonging the duration of breast-feeding, especially where these are delivered in the community ${ }^{27}$. Understanding which women are less likely to adhere to current infant feeding recommendations and why is essential for developing and targeting specific interventions to reduce inequalities in early life as well as the future morbidity associated with early discontinuation of breast-feeding or introduction of solids $^{4,6,7,28}$.

\section{Unanswered questions and future research}

Our study highlights the importance of cultural, social and educational influences on a mother's decisions about how to feed her infant, as well as their varying influence according to maternal ethnic group. As a next step, qualitative research, which has provided important insights into factors affecting maternal feeding intentions ${ }^{29,30}$, might help clarify the pathways linking these factors with the feeding practices reported here. Future research should also examine the implications of these ethnic differences in infant feeding patterns in relation to infant growth, given recent evidence of ethnic differences in growth during infancy ${ }^{31}$.

\section{Conclusion}

We have identified important geographic, ethnic and social inequalities in breast-feeding continuation and introduction of solids within the UK, many of which have not been reported previously. The factors mediating these associations are complex and merit further study to ensure that interventions proposed to promote maternal adherence to current infant feeding recommendations are appropriate and effective.

\section{Acknowledgements}

Sources of funding: The Millennium Cohort Study is funded by grants to Professor Heather Joshi, director of the study, from the ESRC and a consortium of government funders. L.J.G. is funded by an MRC Special Training Fellowship in Health Services \& Health of the Public Research; R.T. and C.D. are funded by HEFCE. Research at the Institute of Child Health and Great Ormond Street Hospital for Children NHS Trust benefits from R\&D funding received from the NHS Executive.

Conflict of interest declaration: None.

Authorship responsibilities: L.J.G. contributed to the conception, study design, analysis and interpretation of the data, and first draft of the article. C.D. contributed to the conception, study design, interpretation of the data and further drafting of the article. R.T. contributed to the study design, analysis and interpretation of the data, and further drafting of the article. All authors have also seen and approved the final version. L.J.G. will act as guarantor for the paper.

Acknowledgements: We would like to thank all the Millennium Cohort families for their cooperation, and the Millennium Cohort Study team at the Centre for Longitudinal Studies, Institute of Education, University of London. The Millennium Cohort Study was approved by the London Multi Centre Research Ethics Committee. The present analyses did not require additional ethics approval.

\section{References}

1 Gartner LM, Morton J, Lawrence RA, Naylor AJ, O'Hare D, Schanler RJ, et al. Breastfeeding and the use of human milk. Pediatrics 2005; 115: 496-506.

2 Department of Health. Weaning and the Weaning Diet. Report on Health and Social Subjects No. 46. London: The Stationery Office, 1994. 
3 World Health Organization (WHO). Infant and Young Child Nutrition. Global Strategy on Infant and Young Child Feeding. Geneva: WHO, 2002.

4 Howie PW, Forsyth JS, Ogston SA, Clark A, du V Florey C. Protective effect of breastfeeding against infection. British Medical Journal 1990; 300: 11-6.

5 Harder T, Bergmann R, Kallischnigg G, Plagemann A. Duration of breastfeeding and risk of overweight: a metaanalysis. American Journal of Epidemiology 2005; 162 397-403.

6 Wilson AC, Forsyth JS, Greene SA, Irvine L, Hau C, Howie PW. Relation of infant diet to childhood health: seven year follow up of cohort of children in Dundee infant feeding study. British Medical Journal 1998; 316: 21-5.

7 Wright CM, Parkinson KN, Drewett RF. Why are babies weaned early? Data from a prospective population based cohort study. Archives of Disease in Childhood 2004; 89: 813-6.

8 Savage SA, Reilly JJ, Edwards CA, Durnin JVGA. Weaning practice in the Glasgow longitudinal infant growth study. Archives of Disease in Childhood 1998; 79: 153-6.

9 Hamlyn B, Brooker S, Oleinikova K, Wands S. Infant Feeding 2000. A Survey Conducted on Behalf of the Department of Health, the Scottish Executive, the National Assembly for Wales and the Department of Health, Social Services and Public Safety in Northern Ireland. London: The Stationery Office, 2002.

10 Fewtrell MS, Lucas A, Morgan JB. Factors associated with weaning in full term and preterm infants. Archives of Disease in Childhood Fetal and Neonatal Edition 2003; 88: F296-301.

11 Griffiths LJ, Tate AR, Dezateux C. The contribution of parental and community ethnicity to breastfeeding practices: evidence from the Millennium Cohort Study. International Journal of Epidemiology 2005; 34: 1378-86.

12 Thomas M, Avery V. Infant Feeding in Asian Families. London: The Stationery Office, 1997.

13 Foote KD, Marriott LD. Weaning of infants. Archives of Disease in Childhood 2003; 88: 488-92.

14 Smith K, Joshi H. The Millennium Cohort study. Population Trends 2002; 107: 30-4.

15 Plewis I. Millennium Cohort Study: Technical Report on Sampling. London: Institute of Education, University of London, 2004.

16 Office for National Statistics. Ethnic Group Statistics: A Guide for the Collection and Classification of Ethnicity Data. London: The Stationery Office, 2003.

17 Rose D, Pevalin D. A Researcher's Guide to the National Statistics Socio-economic Classification. London: Sage Publications, 2003.
18 Zou GA. Modified Poisson regression approach to prospective studies with binary data. American Journal of Epidemiology 2004; 159: 702-6.

19 Githens PB, Glass CA, Sloan FA, Entman SS. Maternal recall and medical records: an examination of events during pregnancy, childbirth, and early infancy. Birth 1993; 20: 136-41.

20 Li R, Scanlon KS, Serdula MK. The validity and reliability of maternal recall of breastfeeding practice. Nutrition Reviews 2005; 63: 103-10.

21 James J, Underwood A. Ethnic influences on weaning diet in the UK. Proceedings of the Nutrition Society 1997; 56: 121-30.

22 Yngve A, Sjostrom M. Breastfeeding in countries of the European Union and EFTA: current and proposed recommendations, rationale, prevalence, duration and trends. Public Health Nutrition 2001; 4: 631-45.

23 Alder EM, Williams FL, Anderson AS, Forsyth S, Florey Cdu V, van der Velde $P$. What influences the timing of the introduction of solid food to infants? British Journal of Nutrition 2004; 92: 527-31.

24 Hammer LD, Bryson S, Agras WS. Development of feeding practices during the first 5 years of life. Archives of Pediatrics E Adolescent Medicine 1999; 153: 189-94.

25 Department of Health. Improvement, Expansion and Reform: The Next 3 Years. Priorities and Planning Framework 2003-2006. London: Department of Health, 2002.

26 Department of Health. Healthy Start: a new welfare food scheme [online]. Available at http://www.dh.gov.uk/PolicyAndGuidance/HealthAndSocialCareTopics/MaternalAndInfantNutrition/MaternalAndInfantNutritionGeneralArticle/ fs/en?CONTENT_ID $=4112476 \& \mathrm{chk}=\mathrm{ycC} / \mathrm{gd}$. Accessed 19 December 2005.

27 Renfrew MJ, Dyson L, Wallace L, D'Souza L, McCormick F, Spiby H. The Effectiveness of Public Health Interventions to Promote the Duration of Breastfeeding. Systematic Review Part 1. London: National Institute for Health and Clinical Excellence, 2005.

28 Fergusson DM, Horwood LJ. Early solid food diet and eczema in childhood: a 10-year longitudinal study. Pediatric Allergy and Immunology 1994; 5: 44-7.

29 Hoddinott P, Pill R. Qualitative study of decisions about infant feeding among women in east end of London. British Medical Journal 1999; 318: 30-4.

30 Hoddinott P, Pill R. A qualitative study of women's views about how health professionals communicate about infant feeding. Health Expectations 2000; 3: 224-33.

31 Tate AR, Dezateux C, Cole TJ, the Millennium Cohort Study Child Health Group. Is infant growth changing? International Journal of Obesity and Related Metabolic Disorders 2006; 30: 1094-6. 